\title{
The consultation in the mental health service in a General Hospital of the Buenos Aires suburbs, Argentina
}

\author{
Fernando J Marzano* \\ Hospital Zonal de Agudos Manuel Belgrano, Salud mental, Área de interconsulta, Argentina
}

In the thought of Ramón Carrillo resolutely sanitary, I thought the mental illnesses in the general context of Medicine, understood as a responsibility of the State. Through rational planning, Carrillo sought to create a common nosographic nomenclature that I've tried to impose from the levels of government to organize, from it, the entire healthcare structure of the specialty. Some of his proposals anticipated ideas of wide subsequent acceptance such as the acute psychiatric hospital, Psychopathology Services in general hospitals and Health Centers, as well as institutions specialized in the treatment of certain groups of patients, while the concern for rehabilitation of the mentally ill opposed to asylum chronification, encouraged his entire National project.

Carrillo advocated a comprehensive conception of health in the preventive and curative, I have taught the rational use of resources and more in poor countries, which required an intelligent reorganization in health organization, which I have called "regionalization of health services Health". Ramón Carrillo, as the last stage of the thesis plan, intended to go beyond a place of assistance, treatment, scientific research, and social service; it would also be a stage of health culture. What is the health policy in conglomerates whose strengths and weaknesses are supine? With what instruments to deal with such situations, beyond deceptive Samaritanisms, are they populated with lying NGOs? Association to help the needy child, you can do it, do it by yourself, come to us and you have a happy future. That icon from the 40 s, where that school of teaching typing and good diction and good writing called pitman showed two young people in profile as the future that horizon that is anticipated. They are images as painful and deceitful as the image of hospital silence with that attractive, pretty nurse who gives us the sign of silence, do not denounce what you see, do not talk about what is happening here, do not proclaim the embarrassing and devious failure of subjugation of these res. $i$ What is the logic of a plan and the political range That sustains it? The implementation of a plan and its obstacle. The ease of executions. ¿ How can we weigh to pre plan? . What political categories? The logic of the plans in the field of the possible. The health plan involves investments. Methods of a particular development plan. Walkable roads for development. Programs and supports?, Available spaces.

The suffering of the being is usually marked by experiences in which many times there are more the conditions of existence, the particular situation that that being has regarding its environment, its habitat and fundamentally in our practice the conflict that we can call human in relation to the alike. The social bond is always going to be defined in a series of invisible rules whose fundamental determinant is still by social context defines those particular beings, singular in relation to their fellow men, the central nucleus of all social condition is the family, the context The family is usually the primary support for the emergence of disorders, pathologies, disease circumstances, certainly linked to the ranges of personality they hold, the fundamental figures of the family such as the father, the mother and in many cases other family members who They participate in the coexistence, grandparents, uncles. These surrounded in a life condition in which the personal vicissitudes of those beings in coexistence are usually determined by the cultural, economic characteristics, and the class implication with which it is determined. In this regard, the conditions that consultation conditions usually have in these hospital settings, if a fundamental basic profile of statistical value could be defined, without doubt, at the same time, is to observe that the conditions of existence suffer the limit very determined by the conditions of stocks, scarcities, provisori ages and socioeconomic certain circumstances indexes that the family exists, lives, and therefore suffers or suffers the effects associated with such conditions.

There is no doubt that in these frequent conditions we tend to find circumstances of a certain family disorder, of a certain family disorder, in which there may be pathologies of other members, in addition to the individual who attends or attends, linked to certain ill conditions ranging from certain eloquent forms of alcoholism fundamentally but not necessarily. They are conditions linked to a needy life in which from the habitat conditions to the food prerequisites that these beings have, they show their effects to the health conditions that they show or manifest. A social view of our practice clinical psychology makes us distinguish these conditions in relation to the context in which we work and the incidence and effect saved and have those findings, observations and determinism will clear our anamne sis and resources of clinical inquiry that we have. These cut and unique patients in contexts very determined by living conditions socially love to attempt to lift, disturbing, as well also working conditions based holding provisoriedades, scarcities and limitations of revenue in relation to the work they can practice. It means that we observe conditions of life restriction in terms of the possibilities and facilitations of elements in terms of access, not from culture or new technology, but access to necessary care and attention to what is an elemental clinical control of beings. They are patients who have not visited a clinician for years with the illusory ways of home medicine with various problems, from the amounts of aggressiveness in which in some families it has the attribute of being a circulating element in the way of vicnulo leading to conflicts. Annoying women who break into positions of violence, there is an

${ }^{*}$ Correspondence to: Fernando J Marzano, Hospital Zonal de Agudos Manuel Belgrano, Salud mental, Área de interconsulta, Argentina, E-mail: fernandojmarzano@gmail.com

Received: April 30, 2020; Accepted: May 07, 2020; Published: May 11, 2020 
extreme restriction of the field of the word. We have found that in these families there is no conversation, there are no conversational elements linked to common interests, much less refer to the difficulties that each member may refer in their relationships, in the daily life and in that sense a closure is at stake. In addition to the educational limitations that they have suffered where their forms of school progress rarely have the quality of an elementary basic average in development and most of the time they have unfinished activities, they have generally completed primary school but did not reach secondary school or remain in the path. It means that they are hatched beings trapped in a relational order where the word does not keep any guiding principle or the ways in which they tend to educate themselves so to speak in the primacy of fear, admonition, constant reproach and more than once the exercise of some threat that according to the ages that go from the reprimand to restrictive prohibitions of an intelligent ordering of a young person or a child or a young adult in those family nuclei that usually exceed in number and therefore the housing conditions show extreme limitations to privacy and the possibilities of personal development gained by cultural, educational or social interests. In these contexts, getting sick today brings a strong dominance of addictions, but not only in the vicious exercise of some intake, but in the round and in the circuit of coexistence, many young people have to avoid the treat or the threat or link on the plans of friendship with other beings, inhabitants of those places where they are usually won by some obstacle where the field of aggressiveness without reaching a certain criminal organization or on the verge of infringing elements as required by law. In this context there is certainly a primacy of a certain irrationality to name it in some way, surely there are beings who escape by their own nature to phenomena of decline and new evolution and possibilities, but these contexts will inexorably limit interests in the possibilities in that rogue way of opportunities. Those high-sounding proclamations of giving opportunities to young people, the conditions that are offered alienate any opportune object, the opportunity to start a job in accordance with the required social laws, and generally enter into labor marginalizations, on the definitive level of certain exploitation, certain abuse in the hourly conditions and many times in the environmental conditions in which they try to develop something. What is the word of these beings? Because they live in illusion, they see the same programs as other beings in the same community, they participate in the same offerings of shows, there are rock offers, there are offers of massive announcements that reach them, offers of objects that they cannot reach. Those glamorous propaganda formulas that show on their flat surface the neatness and joy of a young man partying with a fizzy drink in unison and that the sparkling drink jumps out of the bottles and splashes in phenomenal joy with multicolored lights "the party", for these young people the party is very limited is to hit the peak of a bottle taking turns at a time and from time to time with some brutal violence. That intimate relationship that exists between social perceptions, the cathodic force of television sets, and today we must add the rapid real-time exchanges of new technologies that boast of having them, also strive to have them in many cases. These young people are no longer on the fringes of what field of territory they are in another field very different from another law, another territory, another modality, another code as they say, it is like a virtue, the code of a necessary beating if a certain disloyalty plays in their field. Thus the things, a thought and a reflection of our clinic in those areas finds that our discursiveness is far from being able to reach them because it is not about speaking the same language to be able to reach them, it is not necessary to have a jailer language to be up to the task from them. What can be done to bring them closer to a possible language of understanding to capture when the social fact is dominant and privileges situations that are extremely close to the notion of freedom of these young people. They are young slaves, addiction itself is the condition of their slavery as the word addict itself says. It is then that questioning ourselves about these practices cannot ignore the political registration that is sustained, which I want for my country, for my people, for my fellow men in relation to the conditions of possibility for elemental development since such policies generated by conditions of hegemonies and domains and the primacies of groups strongly conditioned to power establish in these situations greater insolvency conditions for any development [1-7].

\section{References}

1. Carrillo, Ramón (1951) Theory Hospital-1951-. I Complete Works. Eudeba, Buenos Aires.

2. Freud S (1948) The future of an illusion. In: Complete Works. Madrid, New Library.

3. Jameson F, S Zizek (1993) Cultural Studies. Editorial Paidos.

4. Lacan, Jacques (2002) Writings I. (1 Edn) 21st century Editors Argentina.

5. Laclau, Ernesto-Mouffe, Chantal (1987) Hegemony and socialist strategy. Towards a radicalization of democracy, Siglo XXI, Madrid.

6. Svampa M (2005) The exclusive society. Argentina under the sign of neoliberalism. Buenos Aires, Taurus.

7. Viola WB (1967) Social psychiatry. Latin American Publishing Center.

Copyright: (2020 Marzano FJ. This is an open-access article distributed under the terms of the Creative Commons Attribution License, which permits unrestricted use, distribution, and reproduction in any medium, provided the original author and source are credited. 